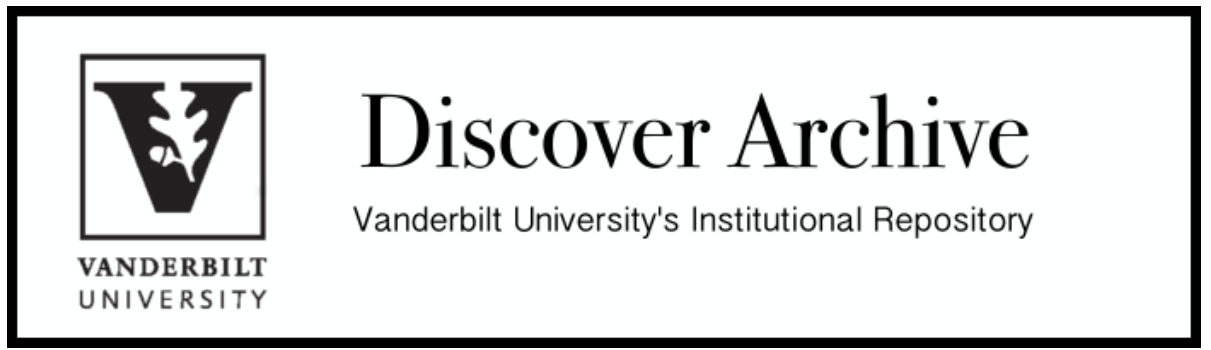

This work was originally published as: W. Kip Viscusi, Joel Huber and Jason Bell, Estimating Discount Rates for Environmental Quality From Utility-Based Choice Experiments - 37 Journal of Risk and Uncertainty 199 (2008). 


\title{
Estimating Discount Rates for Environmental Quality from Utility-Based Choice Experiments ${ }^{*}$
}

\author{
by \\ W. Kip Viscusi, ${ }^{* *}$ \\ Joel Huber, ${ }^{* * *}$ \\ and \\ Jason Bell ${ }^{* * * *}$
}

July 9, 2008

\footnotetext{
* This research was supported by EPA grant R-827423-01-4. Richard Zeckhauser provided detailed, excellent suggestions throughout the manuscript. Gregory M. Duncan, John Horowitz, V. Kerry Smith, and Martin Weitzman provided valuable suggestions. Helpful comments were provided by several seminar participants at the University of Maryland, University of Wyoming, Harvard University, and the NBER.

** University Distinguished Professor of Law, Economics, and Management, Vanderbilt University, $13121^{\text {st }}$ Avenue South, Nashville, TN 37203, kip.viscusi@ vanderbilt.edu.

*** Allan D. Schwartz Professor of Marketing, Fuqua School of Business, Duke University.

**** Fuqua School of Business, Duke University.
} 


\begin{abstract}
We estimate rates of time preference using a utility-based choice experiment administered to a nationally representative sample of 2,914 respondents. For the full sample, the rate of time preference is very high for immediate benefits and drops off substantially thereafter, which is inconsistent with exponential discounting but consistent with hyperbolic discounting. Estimates of the hyperbolic discounting parameter range from 0.48 to 0.61 . Visitors to water bodies have low rates of discount but exhibit hyperbolic discounting, whereas those who do not visit have consistently high rates of discount and low valuations of water quality.
\end{abstract}

Keywords: environment, water, rate of time preference, hyperbolic discounting, stated preferences

JEL Classification: C25, D91, Q25 
Many environmental decisions have significant long-term consequences. That makes the discount rate a prime consideration. In a policy context, the intertemporal preferences of the public will generate political pressures affecting environmental policy decisions. The public's intertemporal preferences may not reflect an economist's view of rational behavior, as documented in the emerging literature on anomalies in discounting behavior. The more important issue is not whether irrationalities exist, but whether they are large and are likely to have consequential effects.

Our approach departs from the existing literature in several ways. First, we estimate rates of time preference based on a series of environmental policy choices administered in a survey context. Rather than using an experimental structure with a small convenience sample, we use a survey methodology that draws on a large nationally representative sample. For this sample, we estimate average and marginal rates of time preference and ascertain how these vary with individual characteristics. Unlike many experimental studies that involve modest but real financial stakes, our experimental structure utilizes stated preferences, which we subject to a variety of internal validity and rationality tests.

Second, we estimate rates of time preference using a random utility model, employing both conditional fixed-effects logit and mixed logit approaches. These estimation approaches incorporate different sets of assumptions; the independence of irrelevant alternatives is the most important. Because our formulations involve estimates of discount rates within the context of individual utility levels over time, they invoke a theoretically appropriate model of discounted utility. This process is more direct than experimental studies that estimate discount rates on money rather than on utility. 
Third, our study examines the pattern of discount rates for water quality improvements over time and evaluates its consistency with exponential discounting and hyperbolic discounting approaches. A principal alternative to exponential discounting is the hyperbolic discounting model, which is distinguished from exponential discounting by a single parameter $\beta$. When this parameter is less than 1 , it characterizes hyperbolic as opposed to exponential discounting.

Section 1 introduces the choice task and describes the national probability-based sample. The environmental good in the choice context is water quality. The other dimensions of the choice are the cost of water quality improvements and the time when the improvements will occur. ${ }^{1}$

Section 2 presents estimates of a random utility model, a conditional fixed-effects logit model, and a mixed logit model. These models yield information on rates of time preference as a function of different periods of delay. The mixed logit models relax two key assumptions of the conditional logit model and permit individual heterogeneity in the parameter values. The two models yield very similar results, showing the results are robust.

In Section 3 we present estimates of the hyperbolic discounting parameter $\beta$ for both the conditional logit and mixed logit cases. A key finding is that the rates of discount and the properties of discount rates for environmental quality differ markedly for people who visit lakes, rivers, and streams for recreational purposes and those who do not. Section 4 examines the nature of these differences. Recreational users of water bodies have higher valuations of water quality and lower rates of time preference, but

\footnotetext{
${ }^{1}$ The literature on discount rates for environmental goods and the role of hyperbolic discounting includes Horowitz and Carson (1990) and Cropper and Laibson (1999).
} 
unlike those who do not use inland water bodies for recreation, they exhibit hyperbolic discounting. Section 4 also explores the influence of other personal characteristics such as age. Section 5 summarizes our results and their implications.

\section{Choice Task and Sample Description}

\subsection{Survey Structure}

Our study uses an original survey in which each respondent considered a policy choice task such as that presented in Figure 1. The general research strategy is to elicit respondents' valuations of environmental improvements that would begin after different periods of delay. Before considering the choices, respondents receive detailed information on three dimensions of the choices: water quality, cost, and time. Respondents make five choices among three policy options, which are defined along these three dimensions. Respondents indicate their most preferred choice among the different policy alternatives.

The environmental dimension is the amount of water quality improvement, which is the percentage of lakes and rivers in the respondent's region that the U.S. Environmental Protection Agency (EPA) rates as being "good" for fishing, swimming, and quality of the aquatic environment. ${ }^{2}$ The percentage improvement ranges from 5 percent to 20 percent. Each of the policies generates costs ranging from $\$ 100$ to $\$ 400$. The time dimension in Figure 1 is the year when improvement begins, which we will refer to below as time delay. The amount of time delay before the improvement is realized is zero, two, four, or six years. Because of the relatively short time delays, the

\footnotetext{
${ }^{2}$ The survey included an extensive discussion of water quality based on the approach taken by the U.S. EPA (1994) in its National Water Quality Inventory. See Huber, Viscusi, and Bell (2008) for further description.
} 
results should not be influenced by how people discount effects that occur after one's death. ${ }^{3}$ The policy choice decisions involved four different levels of cost, four different levels of water quality improvement, and four different periods of time delay.

The survey design makes it possible to identify the individual's rate of time preference for quality improvements. ${ }^{4}$ For each different time delay, the survey permits an estimate of how much the respondent would have been willing to give up in terms of lower water quality or higher cost to remain just as well off. The cost dimension of the policy choice is not needed to estimate this intertemporal tradeoff rate. However, including cost makes the policy choice more realistic and leads to estimates of the costwater quality improvement tradeoff that can be compared with estimates using a different survey methodology as an additional validity check.

\subsection{Modeling the Effect of Delay}

The costs and water quality improvements had comparable time dimensions, with each lasting for five years. However, costs begin immediately while the benefits begin after a period of 0 to 6 years. Thus the time discounting considers the value in present dollars of the level of improvement or of having the improvement come sooner. To see the tradeoff between the present value of costs and improvements, consider the standard exponential discounting case with a constant annual discount factor $\delta$. There is a delay of

\footnotetext{
${ }^{3}$ The choice set led to tradeoffs that were corroborated using quite different survey methodologies. In particular, the water quality-cost tradeoffs were similar to those using a referendum format and an iterative paired comparison format. The choice design was generated using a structure in which alternatives were balanced with respect to utility (Huber and Zwerina 1996). The choice sets are selected to minimize the expected magnitude of the variance-covariance of the estimated parameters given prior estimates of these parameters. The designs that emerge avoid dominant options or easy choices but provide more accurate parameter estimates.

${ }^{4}$ As an identification check, we also estimated a variety of linear and quadratic specifications reported in the Appendix, and the results were robust. See Rust (1994) for further discussion of identification issues.
} 
$\mathrm{t}$ years before the improvement begins. With a delay of t years, the discount factor is $\delta^{\mathrm{t}}$. Let the person's utility function be additively separable and linear in cost $c$ and water quality improvement $w$, and let the time period of delay be t. ${ }^{5}$ Then the present value of the five year imposition of costs beginning immediately, as described in the survey text, is $c\left[1+\delta+\delta^{2}+\delta^{3}+\delta^{4}\right]$. Similarly, the present value of water quality benefits after a $t$ year delay is given by $\mathrm{w}^{\mathrm{t}}\left[1+\delta+\delta^{2}+\delta^{3}+\delta^{4}\right]$. Because the bracketed terms are identical, the person's decision reduces to ascertaining whether the value of $\mathrm{c}$ is greater than $w \delta^{t}$. The value of $\delta=1 /(1+r)$, where $r$ is the rate of interest. Thus, $1 /(1+r)^{t}$ units of water quality that will result from improvements begun immediately will be equivalent to a unit of water quality improvement begun after a period of $t$ years. The cost imposition will be worthwhile if the utility of the water quality improvement in year $t$ is at least as great as $(1+r)^{t}$ multiplied by the utility of the annual cost. The fact that the costs and improvements occur over a five-year period drops out of the analysis, as the bracketed terms in the present value formulas above cancel out when comparing costs and benefits.

We test for the possibility that respondents use hyperbolic discounting rather than exponential discounting. Hyperbolic discounting rates place a greater weight on immediate compared to deferred payoffs, inducing patterns of time inconsistency. Concerns with time inconsistency and hyperbolic discounting date back to Strotz (1956). The widely used quasi-hyperbolic discounting (hereafter merely denoted as "hyperbolic") approach employed by Laibson (1997) is useful because of its analytic simplicity and

\footnotetext{
${ }^{5} \mathrm{We}$ also assume that the discount rate is the same for costs and for improvements. This assumption facilitates the theoretical discussion and is the norm in the literature, but it is not essential for the interpretation of the empirical results because the cost time stream never varies.
} 
clear-cut contrast with the exponential model. The hyperbolic formulation for discrete time periods yields discount factors given by $\left\{1, \beta \delta, \beta \delta^{2}, \beta \delta^{3}, \ldots\right\}$, where $0<\beta<1$, and $\delta<$ 1. The discount factor terms involving $\delta$ are all multiplied by a parameter $\beta$ except in the initial period. The discussion here and below employs discrete rather than continuous time because our survey focuses on discrete periods of time.

Matters become a bit more complicated based on the hyperbolic discounting model. The survey scenario pertains to costs and benefits over a five year period. The present value of the cost stream becomes $c\left[1+\beta \delta+\beta \delta^{2}+\beta \delta^{3}+\beta \delta^{4}\right]$. If the benefits begin immediately, the present value is $w\left[1+\beta \delta+\beta \delta^{2}+\beta \delta^{3}+\beta \delta^{4}\right]$. The policy is attractive if the utility of the annual water quality improvement w exceeds the disutility of the annual cost. If there is a time delay of $t$ years, benefits are $w \beta \delta^{t}\left[1+\delta+\delta^{2}+\delta^{3}+\delta^{4}\right]$. The bracketed expression and the $\beta$ term are present for all nonzero periods of delay. Consider the five year stream of water quality improvement deferred by $t$ years that is equivalent to the disutility of the five year cost stream that begins immediately. Let costs be multiplied by -1 to reflect the fact that cost $\mathrm{c}$ has a negative utility value. The value of w must satisfy

$$
w \delta^{t}\left[\beta+\beta \delta+\beta \delta^{2}+\beta \delta^{3}+\beta \delta^{4}\right]=-c\left[1+\beta \delta+\beta \delta^{2}+\beta \delta^{3}+\beta \delta^{4}\right],
$$

or

$$
\mathrm{w}=\frac{-\mathrm{c}\left[1+\beta \delta+\beta \delta^{2}+\beta \delta^{3}+\beta \delta^{4}\right]}{\delta^{\mathrm{t}}\left[\beta+\beta \delta+\beta \delta^{2}+\beta \delta^{3}+\beta \delta^{4}\right]}>\frac{-\mathrm{c}}{\delta^{\mathrm{t}}} .
$$

Compared to the exponential discounting case, hyperbolic discounting boosts the water quality improvement needed to achieve indifference with the utility of the immediate cost stream. This relationship reflects the general phenomenon that hyperbolic discounting 
differentially reduces the value of all deferred payoffs by a multiplicative parameter $\beta$ in the hyperbolic discounting model.

\section{$\underline{1.3 \text { Sample Characteristics }}$}

In 2004 a group of almost three thousand respondents participated in our Webbased valuation survey. The sample participants were members of the Knowledge Networks panel, which is a probability-based panel so that the composition closely parallels the U.S. Census statistics. People who do not have computers are given free internet access. The response rate to our survey is over 75 percent. As documented in Table A1, the demographic profile of our respondent group is remarkably similar to the mix of the age 18 and over U.S. population. We describe the properties of the sample and present tests of the survey methodology elsewhere. ${ }^{6}$

Although this conjoint survey is not a contingent valuation survey, it is in the general family of stated preference surveys. In the Appendix we report the requisite validity tests that have been established for such studies. ${ }^{7}$ Chief among these tests is a series of scope tests to ascertain whether subjects consistently prefer more water quality improvement to less and, similarly, whether they prefer lower values of costs and shorter delays to higher costs and longer delays. ${ }^{8}$ The survey included an additional series of rationality tests to determine whether subjects made decisions that did not lead to the choice of a dominated alternative. Overall, 95 percent of the original sample, or 2,914

\footnotetext{
${ }^{6}$ Magat, Viscusi, and Huber (2000), Viscusi, Huber, and Bell (2008), and Huber, Viscusi, and Bell (2008) describe these other aspects of the survey, including sample attrition and selection effects. The current paper provides the first analysis of the questions pertaining to rates of time preference.

${ }^{7}$ Arrow et al. (1993) discuss the importance of rationality tests as a validation check for stated preference surveys.

${ }^{8}$ As emphasized by Heberlein, Wilson, Bishop, and Schaeffer (2005), additional types of scope tests can be more informative. Extensive scope test results are reported in Huber, Viscusi, and Bell (2008), including behavioral scope tests and affective scope tests.
} 
individual respondents, passed the dominated choice test and therefore constitute the sample considered here. ${ }^{9}$

The computer-based survey lasted an average of 25 minutes and included detailed information pertaining to the meaning of water quality ratings and financial costs. Each respondent considered a series of five policy choice tasks, such as that in Figure 1, so that there are 14,570 decisions among the three policies.

\section{Empirical Model and Estimates}

\subsection{The Random Utility Model}

To analyze the conjoint decisions we use a random utility model framework. ${ }^{10}$ The three utility components are the cost c, the water quality improvement $w$, and the time delay t. The per unit utilities associated with these components are $\alpha$ for cost, $\lambda$ for water quality, and $\gamma$ for time delay. The attribute $w$ is positively valued, while cost and delay are negatively valued. Let $\mathrm{i}$ denote policy option $\mathrm{i}$ and $\mathrm{n}$ denote respondent $\mathrm{n}$. In a simple model with only main effects, the utility $u_{n i}$ of choice $i$ for respondent $n$ is given by

$$
\mathrm{u}_{\mathrm{ni}}=\alpha \mathrm{c}_{\mathrm{ni}}+\lambda \mathrm{w}_{\mathrm{ni}}+\gamma \mathrm{t}_{\mathrm{ni}}+\varepsilon_{\mathrm{ni}},
$$

where $\varepsilon_{n i}$ is a random error term.

Our primary focus is on a model that includes an interaction of the water quality improvement variable with the time delay to reflect how the respondent discounts water quality improvements over time. Thus, we rewrite the utility as

$$
\mathrm{u}_{\mathrm{ni}}=\alpha \mathrm{c}_{\mathrm{ni}}+\lambda \mathrm{w}_{\mathrm{ni}}+\gamma \mathrm{t}_{\mathrm{ni}}+\theta \mathrm{w}_{\mathrm{ni}} \mathrm{t}_{\mathrm{ni}}+\varepsilon_{\mathrm{ni}}
$$

\footnotetext{
${ }^{9}$ The empirical estimates reported here are very similar to those obtained using the full sample.

${ }^{10}$ For general background, see McFadden (1974) and Train (2003).
} 
The probability $\mathrm{p}_{n i}$ that respondent $\mathrm{n}$ chooses option $\mathrm{i}$ is given by

$$
\mathrm{p}_{\mathrm{ni}}=\operatorname{Prob}\left(\alpha \mathrm{c}_{\mathrm{ni}}+\lambda \mathrm{w}_{\mathrm{ni}}+\gamma \mathrm{t}_{\mathrm{ni}}+\theta \mathrm{w}_{\mathrm{ni}} \mathrm{t}_{\mathrm{ni}}+\varepsilon_{\mathrm{ni}}>\alpha \mathrm{c}_{\mathrm{nj}}+\lambda \mathrm{w}_{\mathrm{nj}}+\gamma \mathrm{t}_{\mathrm{nj}}+\theta \mathrm{w}_{\mathrm{nj}} \mathrm{t}_{\mathrm{nj}}\right) \text {, for all } \mathrm{j} \neq \mathrm{i} \text {. }
$$

Delay consequently may reduce utility directly as well as through its effect on how improvements are valued. These interactions will provide estimates of how the discount rate for water quality improvements varies with the period of delay. The dominant economic effect that should be exhibited under the standard exponential discounting model is a steady exponential decrease in the value of improvements as the length of the delay is increased. Drawing on considerations beyond our model, respondents may be averse to delays wholly apart from the effect on discounting of the stream of benefits. For example, delays frequently are signals of uncertainty as to whether the policy will take effect.

Direct effects of personal characteristics do not enter this comparison in equation 5 since they are common to all choices. However, our conditional logit estimates of the model below will explore the effect of interactions of a vector of personal characteristics with each of the main utility components: $c_{n i}, w_{n i}$, and $t_{n i}$. Thus, these interactions will explore how attributes such as membership in an environmental organization affect preferences over different components.

The effect of visiting lakes and rivers for recreational purposes will be examined in two ways. First, visitor status is a demographic variable, and it can be included among the personal characteristic interactions for estimates based on the full sample. However, visitation of water bodies could also affect the structure of the equation more generally. 
As a result, we also present estimates for the subsample of respondents who visited a lake or river in the past year as well as estimates for those who did not. ${ }^{11}$

The conditional fixed-effects logit model imposes two key assumptions. The more restrictive assumption is that the random components within each subject are not correlated, which leads to the assumption of independence of irrelevant alternatives. A second key assumption is that the variation in preferences is captured by observed respondent characteristics included in the model. Below we present comparative results based on a mixed logit framework that relaxes the independence of irrelevant alternatives assumption and permits there to be unobserved heterogeneity in tastes.

\subsection{Conditional Logit Estimates}

Because the delay variable can take on only three nonzero values of two (Delay 2), four (Delay 4), and six (Delay 6) years of delay, we examine a discrete variable specification for each of these delay periods. The Appendix presents sensitivity tests using other formulations. The model that captures the full range of the time dimensions in the survey is given by

$$
\mathrm{u}_{\mathrm{ni}}=\alpha \mathrm{c}_{\mathrm{ni}}+\lambda \mathrm{w}_{\mathrm{ni}}+\gamma \mathrm{t}_{\mathrm{ni}}+\xi_{1} \mathrm{w}_{\mathrm{ni}} \text { Delay } 2+\xi_{2} \mathrm{w}_{\mathrm{ni}} \text { Delay } 4+\xi_{3} \mathrm{w}_{\mathrm{ni}} \text { Delay } 6+\varepsilon_{\mathrm{ni}} \text {. }
$$

The first column of conditional logit results in Table 1 indicate that the effect on the utility of improvements of a two-year delay is more than half the effect of a six-year delay. The estimates can also be used to calculate the discount factor, or similarly the implied rate of interest. Consider the general case of an $n$ year delay, for $n=2,4$, and 6 .

\section{Since}

\footnotetext{
${ }^{11}$ All estimates are based on the STATA conditional (fixed-effect) logit estimates. The fixed effects are for the different conjoint question sets.
} 


$$
\lambda \delta^{n}=\lambda+\xi_{n},
$$

the value of $\delta$ is given by

$$
\delta=\left[1+\xi_{n} / \lambda\right]^{1 / n}
$$

The substantial influence of early delays is reflected in the estimated rates of time preference, which are summarized in the top panel of Table 2. For a two-year delay, respondents exhibit a 14.3 percent rate of interest. The utility loss associated with a fouryear delay is very similar to that of a two-year delay, with the consequence being that the average rate of time preference is 8.4 percent. For the six-year delay, the average implied rate of interest over that period is 8.7 percent, which is also well below the initial value of 14.3 percent.

The value of $\delta$ given by equation 8 is a nonlinear function of the parameters $\lambda$ and $\xi_{\mathrm{n}}$. It is nevertheless feasible to construct 95 percent confidence intervals for $\delta$, which are $(0.86,0.90)$ for a two-year delay, $(0.91,0.94)$ for a four-year delay, and $(0.90,0.94)$ for a six-year delay. These estimates for $\delta$ in turn imply confidence intervals for the rates of time preference $r$, which in terms of interest rate percent, are $(11.8,17.0)$ for a two-year delay, $(6.6,10.4)$ for a four-year delay, and $(6.7,10.7)$ for a six-year delay. Note that

confidence intervals for the four-year and six-year delay are quite similar. The distinctive confidence interval is for the two-year delay, which is reflective of respondents' very different rate of time preference for the more immediate period of delay.

\section{$\underline{\text { 2.3 Mixed Logit Model }}$}

To explore the robustness of the conditional fixed-effects logit estimates, we also estimate the equations in Table 1 using a mixed logit model. The mixed logit model 
generalizes the conditional logit model on several dimensions. First, it does not require the independence of irrelevant alternatives assumption of the conditional logit framework. Second, rather than assuming homogeneous preferences and estimating a single parameter for each variable, the mixed logit model yields estimates of the mean and variance of the individual level parameters, thus providing information on the extent of individual variation in the coefficient estimates. Third, the estimation approach we use takes into account unobserved factors that will affect particular policy choices by the respondent, leading to possibly correlated errors across the repeated choices. The utility of person $\mathrm{n}$ of policy $\mathrm{i}$ in choice set $\mathrm{k}$ for the analog of equation 4 is

$$
\mathrm{u}_{\text {nik }}=\alpha_{\mathrm{n}} \mathrm{c}_{\text {nik }}+\lambda_{\mathrm{n}} \mathrm{w}_{\text {nik }}+\gamma_{\mathrm{n}} \mathrm{t}_{\text {nik }}+\theta_{\mathrm{n}} \mathrm{w}_{\text {nik }} \mathrm{t}_{\text {nik }}+\varepsilon_{\text {nik }} .
$$

Note that compared to the parameter estimates in equation 4 above, the values of $\alpha, \beta, \gamma$, and $\theta$ are now permitted to vary across individuals in the sample. However, for each of the five choice sets, the values of $\alpha_{n}, \lambda_{n}, \gamma_{n}$, and $\theta_{n}$ are required to be the same across the choices for the particular individual.

The particular estimation approach used is the hierarchical Bayes estimation procedure, which shares the same behavioral model as does the mixed logit model and yields estimates virtually equivalent to mixed logit. ${ }^{12}$ The coefficient vector is assumed to be independent of the stochastic $\varepsilon$ and non-stochastic $\mathrm{c}, \mathrm{w}$, and t.

\footnotetext{
${ }^{12}$ For discussion of the properties of hierarchical Bayes estimates, see Huber and Train (2001) and Train (2003). The hierarchical Bayesian estimation procedure assumes that each individual's parameters can be estimated by a mixture of the aggregate distribution of values with choices that the respondent makes. The mixed logit estimation approach assumes that the parameter vector is normally distributed with mean $\mathrm{b}$ and covariance $\mathrm{W}$, and the error term $\varepsilon_{\text {nik }}$ is iid extreme value. The hierarchical Bayes procedure treats $\mathrm{b}$ and $\mathrm{W}$ as stochastic. Both procedures use simulation methods to derive their estimates. The approach takes as its prior estimate of the parameters coefficient values that account for the derived heterogeneity across respondents and the individual's choices. Combining the prior with the likelihood function for the data yields the posterior distribution. Gibbs sampling is then used to take repeated measures of $\mathrm{b}$ and $\mathrm{W}$ from the posterior distribution. Draws are repeated until the conditional posterior estimates converge. As shown in Huber and Train (2001), the hierarchical Bayes estimates are virtually equivalent to those yielded by
} 
The estimates in the second column of Table 1 present the mean value of the estimated coefficients across the sample as well as the standard deviation of the individual coefficients' values. The various coefficients associated with the delay terms have associated standard deviations that are fairly large relative to the means, indicating quite substantial heterogeneity in rates of discount across respondents.

The mean values of the mixed logit parameters indicate tradeoff rates that closely parallel the conditional logit results. Because the utility scale is invariant with respect to a positive linear transformation, it is the coefficient ratios and relative coefficient values that are most instructive.

The similarity of the conditional logit and mixed logit estimates is apparent in Figure 2, which illustrates the discount factors for improvements occurring with different periods of delay based on a continuous, quadratic time delay formulation in Table A3. For the first three years of delay, the discount factors are almost identical for the conditional fixed-effects logit and mixed logit estimates. Thereafter the discount factor implied by the mixed logit estimates becomes increasingly greater than that implied by the conditional logit model, which reflects the somewhat lower average rate of time preference implied by the mixed logit results.

\subsection{Average and Marginal Rates of Time Preference}

The bottom panel of Table 3 summarizes the average rate of interest implied by this set of mixed logit estimates, which are 12.7 percent for a two-year delay, 8.0 percent

classical maximum likelihood mixed logit approaches. The mean and variance of the Bayesian estimator are asymptotically equivalent to the classical maximum likelihood estimates. Moreover, the hierarchical Bayes estimation is less subject to problems of identification. 
for a four-year delay, and 7.9 percent for a six-year delay. This pattern accords with the hyperbolic discounting model in that there is a very high initial rate of discount followed by a decline and comparative flattening of the rate of time preference. Unlike the conditional logit results, there is no minor increase in the point estimate of the average rate of time preference with a six-year delay.

The unusual pattern of discounting associated with these results can be illustrated by examining the term structure of the implied rates of interest. Let $\mathrm{r}_{\mathrm{fg}}$ be the implied annual rate of time preference for the time period extending from period $\mathrm{f}$ to period $\mathrm{g}$. Consider the estimates using the time delay interval variables for both the conditional logit and mixed logit models. The first column of Table 3 summarizes the pattern of discount factors $\delta_{0 \mathrm{~g}}$ which equals $\delta^{\mathrm{n}}$ for an n-period delay. Column 2 summarizes the average rates of time preference $r_{0 g}$. The substantial weight placed on initial payoffs and the decline in average rates of time preference are inconsistent with the standard exponential discounting model. The steepness of the decline in rates of time preference after the initial period generates an additional anomaly in the discounting pattern.

Following the literature on term structure of interest rates, one can calculate the marginal discount rate for each two-year period. For the first two-year period, the average rate of time preference and the marginal two-year rate of time preference are 14.3 percent for the conditional logit estimates. The marginal value of the rate of time preference over the period extending from period 2 to period 4 for the conditional logit model is the value of $r_{24}$ that satisfies

$$
(1+0.084)^{4}=(1+0.143)^{2}\left(1+r_{24}\right)^{2}
$$

or $\mathrm{r}_{24}=2.8$ percent. Table 3 also reports the marginal rates of time preference for the six- 
year time delay for the conditional logit results as well as parallel results for the mixed logit estimates. For each set of estimates, the results display a common general pattern. Because the high average rate of interest over different periods of delay exhibits a sharp decline and then remains relatively flat, the marginal rate of time preference drops substantially and then increases. To achieve the great drop in the average rate of time preference for four years of delay, the marginal rate must drop considerably. However, because the average rate of time preference declines for a six-year delay but not greatly, the marginal rate of time preference subsequently rises. For both the conditional logit results and mixed logit results, there is an intriguing pattern for marginal rates of time preference which start at a very high level, drop substantially, and then increase.

The pattern of discount factors associated with a $\mathrm{g}$ year delay, which is denoted by $\delta_{0 \mathrm{~g}}$, also is anomalous. Based on the empirical structure of the model, $\delta_{00}$ is set equal to 1.0. As shown in Table 3, under the exponential discounting case, the value of $\delta_{02}=$ 0.77 for the conditional logit model and 0.79 for the mixed logit should be the square of their respective average annual discount factors of 0.88 and 0.89 . Similarly, if $\delta_{04}=0.72$ (conditional logit) or 0.74 (mixed logit), then the associated constant annual value of $\delta$ is given by 0.92 (conditional logit) and 0.93 (mixed logit). These discount factors are above the annual value for the initial two-year delay. Finally, for $\delta_{06}=0.61$ (conditional logit) and 0.63 (mixed logit), the implied annual value of $\delta$ assuming exponential discounting is 0.92 (conditional logit) and 0.93 (mixed logit). The implied annual discount factor assuming exponential discounting begins at a low level, then rises and flattens out. The increase then the flattening in the annual discount factor generates a 
fairly steady decline in the average total discount factor and a more jagged pattern in the marginal rate of time preference.

\section{The Hyperbolic Discounting Parameter $\beta$}

The analysis thus far has presented estimates of annual discount factors based on the exponential discounting framework. It is clear from the observed discount rate pattern that the results are inconsistent with this formulation and have the general characteristics associated with the hyperbolic discounting model. If we recast the results in the hyperbolic discounting framework, it is possible to generate estimates of the hyperbolic discount rate parameter $\beta$ that governs the extent of the departure from exponential discounting.

First, consider the implications of the conditional logit results. The utility of a one unit improvement with a two-year delay is $\beta \delta^{2} w\left[1+\delta+\delta^{2}+\delta^{3}+\delta^{4}\right]$, which is 0.114 based on the coefficient estimates. Similarly, the utility of a unit improvement with a four-year delay is $\beta \delta^{4} w\left[1+\delta+\delta^{2}+\delta^{3}+\delta^{4}\right]$, which is 0.107 . The ratio of these utilities is $\delta^{2}$, which produces an estimate of $\delta$ of 0.969 . Taking the ratio of the zero delay utility to the utility after a two-year delay produces

$$
\frac{0.148}{0.114}=\frac{\mathrm{w}\left[1+\lambda \delta+\lambda \delta^{2}+\lambda \delta^{3}+\lambda \delta^{4}\right]}{\beta \delta^{2} \mathrm{w}\left[1+\delta+\delta^{2}+\delta^{3}+\delta^{4}\right]} .
$$

After substituting for the value of $\delta$ of 0.969 , equation 11 yields a value of $\beta$ of $0.48 .{ }^{13}$

\footnotetext{
${ }^{13}$ This calculation assumes that respondents processed the five year period of water quality improvements, which appears twice in the survey text in Figure 1. Post-survey debriefings of respondents revealed no evidence of misunderstanding of the length of the period of improvement and did indicate explicit awareness of the length of the period.
} 
Analogously, one could have used the estimate of $\delta$ implied by the ratio of the six-year delayed improvement to the two-year delay. Because of the change in rates of time preference over time, this approach yields a somewhat different estimate of $\delta$ of 0.943 , which implies a value of $\beta$ of 0.58 .

One can generate similar estimates based on the mixed logit results. Using the two-year and four-year delay results we generate a value of $\delta$ of 0.967 and a value of $\beta$ of 0.53. With the six-year versus two-year delay as the initial contrast, $\delta=0.948$ and $\beta=$ 0.61. The final column of Table 3 summarizes these results.

Both the conditional logit and mixed logit estimates reflect a similar pattern, with $\beta$ ranging from 0.48 to 0.61 , with the higher values derived from the $\delta$ values based on the longer periods of delay. ${ }^{14}$ In each case, however, the discrepancy between the values of $\beta$ and 1.0 serves as a measure of the extent of departure from the exponential discounting model.

\section{Water Recreational Visitor Status and Discounting Anomalies}

The analysis thus far has abstracted from differences in the preferences among the sample population, estimating average values across the entire sample. As the mixed logit estimates demonstrated, there is considerable heterogeneity in the value of water quality and rates of time preference. In this section we examine a chief source of this heterogeneity based on whether the respondent visits lakes, rivers, and streams for recreational purposes.

\footnotetext{
${ }^{14}$ For interesting results regarding market choices and a review of estimates of the hyperbolic discounting parameter, which are in the 0.5 to 0.8 range, see DellaVigna and Malmendier (2006).
} 
A considerable environmental literature has grappled with the use/nonuse distinction in the valuation of environmental goods. ${ }^{15}$ One would certainly expect visitors to water bodies to express a higher unit benefit value for water quality improvements than those who do not visit. Our emphasis is quite different in that our fundamental concern is with how rates of time preference differ among population groups depending on their water quality visitor status. How benefit values are affected by the timing of the improvements is hardly clear-cut. Because visitors will benefit directly and immediately from water quality improvements, one might hypothesize that visitors will have higher rates of time preference with respect to these improvements. Alternatively, the visitors' valuations of water quality improvement may not decline substantially with delays, because their greater long-term commitment to the improved water will make them more willing to be patient with respect to the timing of the improvement.

The intertemporal rationality of choices may also differ by visitor status. Two competing effects are at work. Those who have visited lakes or rivers more recently have more experience with the good and should be expected to have given more thought to their valuations of water quality improvements at different points in time. As a consequence, their valuations should more closely accord with principles of economic rationality to the extent that such direct experience with the commodity being valued leads to improved economic properties of choices. A countervailing influence is that visitors to lakes and rivers may have become more emotionally attached to the good. As

\footnotetext{
${ }^{15}$ These explorations have also sought to explore related issues such as option values and different forms of passive use. See, among others, Smith (1987), Bishop and Welsh (1992), Smith and Osborne (1996), and Carson, Flores, and Mitchell (1999). We will have a narrower empirical distinction based on water body visits in the past year.
} 
Loewenstein (2000) has hypothesized, the presence of an affective response may induce apparently irrational economic behavior.

Table 4 reports results for different samples based on water body visitor status, where these equations include the main effect of delay and water quality improvement as well as their interaction. Recreation visitors consist of those respondents who have visited lakes, rivers, or streams in the past year. To explore how the rate of time preference may change with the extent of delay, we use a flexible model in which there is a separate interaction for each of the three different periods of delay included in the survey.

As one might expect, water body visitors have a higher benefit value for water quality than those who do not visit. The marginal benefits for a one percent improvement in the amount of water rated "Good" in one's region is $\$ 23.02$ for the full sample, $\$ 24.72$ for the sample who visit lakes or rivers, and $\$ 19.04$ for those who do not visit. Consistent with our hypothesis, those who visit lakes or rivers have a higher value. More specifically, the visits subsample has a valuation with a 95\% confidence interval of (\$23.68, \$25.74), as compared to $(\$ 17.80, \$ 20.53)$ for those who have not visited lakes or rivers in the past 12 months. ${ }^{16}$ It is especially noteworthy that the valuations for those who do not visit lakes or rivers are still reasonably high and are about three-fourths of the size of the valuations of those who have visited lakes or rivers in the past year. These differences can be traced to differences in the water quality utilities, as the cost disutilities are virtually identical for the two subsamples.

Delay has a negative disutility for each of the three sets of estimates. That this disutility value is considerably smaller when the delay-water quality improvement

\footnotetext{
${ }^{16}$ The $95 \%$ confidence interval for the full sample valuation is $(\$ 22.19, \$ 23.85)$.
} 
interactions are included is not surprising. The direct disutility of delay is much lower for the no visits subsample than for the visits subsample. These results indicate that the visits subsample dislikes delays per se in addition to disliking the delayed value of improvement.

Visitors have a surprisingly flat pattern of coefficients for the interactive effect of delays and improvement. Their relatively low discount rate implies that they both value immediate improvement and are willing to wait for improvements. Indeed, the point estimates for the Delay 4 interaction are of smaller magnitude than for the Delay 2 interaction. The increasingly negative coefficient pattern of the delay and improvement interactions for the no visits subsample is more in line with what one would expect based on conventional exponential discounting models.

The bottom two panels of Table 2 summarize the discount rates results for each of the sets of estimates and for each different period of time delay. The visits subsample has much lower rates of time preference than does the no visits subsample. Whereas the visits subsample has rates of time preference in a fairly reasonable range of 5-10 percent, the estimates for the no visits subsample are in the 17-23 percent range, implying considerable discounting of deferred environmental improvements. The no visits subsample has both a higher level of initial desire for water quality and greater patience for awaiting the improvements. For both the full sample and the no visits subsample, the confidence interval for the discount factors for the 0-2 year period does not overlap with that for longer periods of delay, which is consistent with hyperbolic discounting. However, there is substantial overlap for the visits subsample, as is consistent with exponential discounting. For the visitors subsample, the rate of time preference is just 
below 11 percent for the two year delay but is in the 5-6 percent range thereafter. This emphasis on more immediate rewards followed by a discontinuous drop in the rate of time preference that remains steady thereafter is quite consistent with models of hyperbolic discounting. The no visits subsample does not exhibit this pattern.

To explore the influence of personal characteristics on valuations, Table 5 reports results for which each of the main effects is interacted with a full set of demographic variables. In addition to the usual measures pertaining to age, race, gender, education (in years), and income (in thousands of dollars), we also include an environmental group member variable and a lake acres per state square mile variable, each of which should be positively related to valuations. The full sample equation also includes a final set of interactions for whether the respondent visited a lake or river in the past 12 months. The main effects in the results in Table 5 exhibit the same general pattern as in the previous estimates.

The first set of personal characteristic interactions is with the cost of the policy, which has a negative effect on utility in its main effect so that negative interaction terms imply greater cost disutility and positive interaction terms imply less cost disutility. The only interaction that is statistically significant for the no visits subsample is that for environmental group members, who have a positive interaction effect. Those who do not visit lakes or rivers but who nevertheless belong to a major environmental organization experience less of a loss in utility from increases in the cost of water quality improvements, as one might expect. For the sample that visited lakes or rivers in the past year, there is less of a utility loss from policy costs for respondents who are older, have higher income, or are members of an environmental group. The one consistent pattern in 
all three sets of cost interaction estimates is that members of environmental groups experience less of a drop in utility due to higher costs. In the full sample regression, respondents who are black, female, or who have higher income also suffer less of a decline in utility due to policy costs. For the full sample regressions, there is no statistically significant effect on the disutility of costs for those who have visited a lake or river in the past twelve months.

That is not the case for water quality improvements, as people who have visited lakes or rivers have a higher utility value for improvements. Thus, the difference in the tradeoff rate of costs and improvements for the visits subsample as compared to the no visits subsample stems from their different valuation of improvements rather than differences in the disutility of costs. Water quality improvements have fairly homogeneous utility values throughout the no visits population, as none of the interaction terms is statistically significant for this group. However, for both the visits sample and the full sample, there is a negative effect of age and for black respondents, as well as a positive effect of education. Older respondents generally tend to have a shorter time horizon for valuing environmental improvements, and black respondents tend to have much lower usage rates for lakes and rivers than white respondents in our sample, and this influence may reflect their lower intensity of use even if they have visited a lake or river in the past year. More highly educated respondents, who tend to have greater lifetime wealth, value improvements more highly, which is consistent with water quality being a normal good.

The next set of interactions pertains to the effect of delay. The visits group of respondents displays a greater concern with delay than the no visits group. For each of 
the three columns of estimates, older respondents are more averse to delay, which is reflective of their shorter time horizon. Environmental group members also experience greater utility loss from delay in the visits subsample. A striking result is the large negative effect for respondents who are black for all three sets of estimates. While black respondents constitute a small segment of our visits subsample, the lower sensitivity to cost and greater sensitivity to delay may reflect substantial value placed on immediate policy implementation.

\section{Conclusion}

The choice-based conjoint results provide insight into both the level of valuations of water quality and how these values are affected by delays. The respondents to the representative national stated preference survey exhibited many reasonable patterns of behavior. They prefer higher levels of water quality to less and lower cost levels to higher costs. They are also willing to trade off these dimensions now for greater improvements in the future.

The main anomaly that was identified pertained to the temporal structure of discount rates. The full sample exhibited high rates of discount when evaluating immediate improvements, where the discount rate declined and became stable. This pattern is consistent with hyperbolic discounting but not exponential discounting. A particularly striking implication of the discount rate results is that marginal discount rates start out very high, drop precipitously, and then return to a more intermediate level.

Interestingly, there is a stark contrast between those who visit lakes and rivers for recreational purposes and those who do not. Those who do not visit lakes or rivers place 
a lower value on water quality generally but also have a consistently high rate of time preference on the order of 17-23 percent. Given that many environmental amenities have long-term implications, it is quite interesting that the non-visitor sample who exhibit very large rates of time preference also place little value on immediate environmental improvements. Although it is not clear that there is a causal linkage, we would offer the conjecture that people who generally have little concern with the future simply don't place great value on environmental amenities, irrespective of when the improvements are occurring.

Visitors to lakes and rivers value water quality more highly and are also more willing to tolerate delays in water quality improvements, with discount rates in the 5-10 percent range. However, unlike non-visitors, the visitors exhibit a statistically significant pattern of hyperbolic discounting, thus displaying a greater intertemporal preference for immediate improvements that is not consistent with exponential discounting. Although the causal mechanism is not clear, such a pattern conceivably could be due to a greater affective response to water quality on the part of visitors.

Although the presence of hyperbolic discounting is an interesting empirical curiosity, its main effect will be to disadvantage short-term environmental policies. In terms of the average discount factor applied to policies, it is only the initial effects that receive an inordinately high weight. The average discount factor thereafter is quite stable. If such a pattern persists with respect to very long-term payoff streams such as those associated with climate change policies, the influence of the initial hyperbolic discounting anomaly will be negligible. What is of greater consequence is that those who do not visit lakes or rivers have consistently high rates of time preference and place a 
very low value on future economic improvements. This segment of the population will provide little support for environmental policies that generate benefits either now or in the future. 
References

Arrow, Kenneth, Robert Solow, Paul R. Portney, Edward E. Leamer, Roy Radner, and Howard Schuman. (1993). "Report of the NOAA Panel on Contingent Valuation," Federal Register 58, 4601-4614.

Bishop, Richard C., and Michael P. Welsh. (1992). "Existence Values in Benefit-Cost Analysis and Damage Assessment," Land Economics 68(4), 405-417.

Carson, Richard T., Nicholas E. Flores, and Robert C. Mitchell. (1999). "The Theory and Measurement of Passive-Use Value.” In Ian J. Bateman and Kenneth G. Willis (eds.), Valuing Environmental Preferences. New York: Oxford University Press.

Cropper, Maureen L., and David Laibson. (1999). “The Implications of Hyperbolic Discounting for Project Evaluation.” In Paul Portney and John P. Weyant (eds.), Discounting and Intergenerational Equity. Washington, DC: Resources for the Future.

DellaVigna, Stefano, and Ulrike Malmendier. (2006). "Paying Not to Go to the Gym," American Economic Review 96(3), 694-719.

Frederick, Shane, George Loewenstein, and Ted O’Donoghue. (2002). “Time Discounting and Time Preference: A Critical Review," Journal of Economic Literature $\mathrm{xl}, 351-401$.

Heberlein, Thomas A., Matthew A. Wilson, Richard C. Bishop, and Nora Cate Schaeffer. (2005). "Rethinking the Scope Test as a Criterion for Validity in Contingent Valuation," Journal of Environmental Economics and Management 50, 1-22. 
Horowitz, John, and Richard T. Carson. (1990). "Discounting Statistical Lives,” Journal of Risk and Uncertainty 3, 403-413.

Huber, Joel, and Kenneth E. Train. (2001). "On the Similarity of Classical and Bayesian Estimates of Individual Mean Partworths," Marketing Letters 12, 259-269.

Huber, Joel, W. Kip Viscusi, and Jason Bell. (2008). "Reference Dependence in Iterative Choices," Organizational Behavior and Human Decision Processes, in press.

Huber, Joel, and Klaus Zwerina. (1996). "The Importance of Utility Balance in Efficient Choice Designs," Journal of Marketing Research 33, 307-317.

Laibson, David. (1997). “Golden Eggs and Hyperbolic Discounting," Quarterly Journal of Economics 112(2), 443-477.

Loewenstein, George. (2000). "Emotions in Economic Theory and Economic Behavior," American Economic Review Papers and Proceedings 90(2), 426-432.

Magat, Wesley A., W. Kip Viscusi, and Joel Huber. (2000). “An Iterative Choice Approach to Valuing Clean Lakes, Rivers, and Streams," Journal of Risk and Uncertainty 21(1), 7-43.

McFadden, Daniel. (1974). “Conditional Logit Analysis of Qualitative Choice Behavior.” In Paul Zarembka (ed.), Frontiers in Econometrics. New York: Academic Press.

Rust, John. (1994). “Structural Estimation of Markov Decision Processes.” In R.F. Engle and D.L. McFadden (eds.), Handbook of Econometrics Volume IV. Amsterdam: Elsevier Science.

Smith, V. Kerry. (1987). “Non-Use Values in Benefit-Cost Analysis," Southern Economic Journal 54, 19-26. 
Smith, V. Kerry, and Laura L. Osborne. (1996). “Do Contingent Valuation Estimates Pass a 'Scope' Test? A Meta-Analysis," Journal of Environmental Economics and Management 31(3), 287-301.

Strotz, Robert. (1956). "Myopia and Inconsistency in Dynamic Utility Maximization," Review of Economic Studies 23, 165-180.

Train, Kenneth E. (2003). Discrete Choice Methods with Simulation. Cambridge: Cambridge University Press.

United States Environmental Protection Agency. (1994). National Water Quality Inventory, 1992 Report to Congress, EPA 841-R-94-001.

Viscusi, W. Kip, Joel Huber, and Jason Bell. (2008). “The Economic Value of Water Quality," Environmental and Resource Economics. DOI 10.1007/s10640-0079186-4. 


\section{Appendix: Scope and Sensitivity Tests}

The first set of empirical estimates to be explored is the basic model that includes only main effects. These estimates are informative in confirming that higher cost levels and longer delays are negatively valued and larger improvements are positively valued, as required for the scope test.

Table A2 presents two sets of regression estimates of equation 3 for two different samples, where the first sample considers the responses only to the initial conjoint question and the full sample includes five observations per respondent. The conditional logit estimates for Question 1 include only a single observation for each respondent and thus constitute a more rigorous across-subjects scope test. Put differently, the coefficients indicate if the person in the first choice is appropriately sensitive to the three parameters. The coefficients have the expected signs with more water quality improvements raising the probability that the alternative is chosen, whereas there is a negative effect of both delay and cost. The magnitudes of the effects are very similar for both Question 1 and the full sample. In each case, all coefficients are statistically significant at the 99 percent level, two-tailed test. Table A2 reports a second set of regression estimates for each of the two samples using the discrete form of each of the policy choice variables by creating dummy variables for three of the four possible variable values. In addition to exhibiting the hypothesized signs, the magnitudes of the variables follow the expected pattern, as larger water quality improvements are increasingly valued and longer delays and higher cost levels become increasingly unattractive. 
These results can also be used to derive the willingness to pay for water quality.

Taking the total derivative of utility and setting it equal to zero yields

$$
\mathrm{du}=\alpha \mathrm{dc}+\lambda \mathrm{dw}+\gamma \mathrm{dt}=0 .
$$

The marginal value of each unit increase in water quality is given by the marginal rate of substitution between $\mathrm{c}$ and $\mathrm{w}$, or

$$
\frac{\partial \mathrm{c}}{\partial \mathrm{w}}=\frac{-\lambda}{\alpha},
$$

which is $\$ 24.96$ for the Question 1 estimates and $\$ 23.17$ for the full sample. ${ }^{17}$ Because our interest in the Question 1 sample is only from the standpoint of an across-subjects scope test, the subsequent analysis focuses on the full sample.

To calculate the rate of discount implied by these results, consider the overall tradeoff between improvement and delay. This marginal tradeoff rate is given by

$$
\frac{\partial \mathrm{w}}{\partial \mathrm{t}}=\frac{-\gamma}{\lambda}
$$

which is 2.235 for the Question 1 estimates and 2.186 for the full sample. For the midpoint survey water quality improvement level of 12.5 percent, the equivalent water quality with one year of delay based on the full sample estimates satisfies

$$
12.5=\frac{12.5+2.186}{1+\mathrm{r}}
$$

where solving for $r$ yields an average value of $r$ of 17.49 percent. The analogous result for the Question 1 responses is 17.88 percent. These estimates of the discount rate are drawn from an oversimplified model that does not permit possible interactions between time delays and improvements.

\footnotetext{
17 These values are very similar to the estimates generated with a different survey methodology reported in Viscusi, Huber, and Bell (2008).
} 
Although respondents may have preferences regarding policy delays generally, the main matter of interest is how delays affect their valuation of water quality improvements and what rates of discount are implied by these preferences. The first set of estimates in Table A3 adds a Delay x Improvement interaction term to the main effects equation. The utility gain associated with water quality improvements should be smaller for longer delays $t$, and the empirical estimates yield the expected negative effect of the interaction of time delay and water quality improvement. Whereas one unit of immediate water quality improvement has a value of 0.1438 , the value of an improvement that occurs after one year is $(0.1438-0.0086)=0.1352$, dropping to $(0.1438-6 \times 0.0086)=$ 0.0922 by year 6 . This simple interaction constrains the effect of delay to be a constant value of improvement irrespective of the extent of delay. ${ }^{18}$

To provide a more realistic picture of how the length of delay affects the discount rate, the second equation estimated in Table A3 includes a quadratic delay interaction with improvement. This specification permits there to be nonlinearity in the influence of delay on the valuation of improvements, leading to

$$
\mathrm{u}_{\mathrm{ni}}=\alpha \mathrm{c}_{\mathrm{ni}}+\lambda \mathrm{w}_{\mathrm{ni}}+\gamma \mathrm{t}_{\mathrm{ni}}+\theta_{1} \mathrm{w}_{\mathrm{ni}} \mathrm{t}_{\mathrm{ni}}+\theta_{2} \mathrm{w}_{\mathrm{ni}} \mathrm{t}_{\mathrm{ni}}{ }^{2} .
$$

The value of $\theta_{1}$ is negative, and $\theta_{2}$ is positive, indicating a diminishing effect of delay on the utility of improvements.

The quadratic specification generates the temporal pattern of discounting that is consistent with the hyperbolic discounting model. A one-year delay has an associated rate of time preference of 10.6 percent. This average rate of time preference declines to

\footnotetext{
${ }^{18}$ As a result, the marginal effect of long delays on the implied rate of time preference is greater for long delays than for short delays. The implied average rate of discount is 6.4 percent for a one period delay, 6.7 percent for the midpoint delay value of three years, and 7.7 percent for the upper bound delay period of six years. This rising pattern of rates of time preference is the opposite of the hyperbolic discounting pattern, but derives as a consequence of the constraints imposed on the estimation.
} 
10.4 percent for two years, 10.0 percent at the midpoint delay value of three years, 9.7 percent for four years, 9.2 percent for five years, and 8.5 percent for six years. Though these rates of time preference seem high relative to the cost of capital and discount rates used by the government, these estimates are in a more reasonable range than have been found in many studies of real world choices in product markets and the labor market. ${ }^{19}$

${ }^{19}$ Some discount rates have been estimated to be 30 percent or more. Past analyses include the implied discount rates based on appliance energy efficiency decisions, used car purchases, and decisions involving risky jobs. Frederick, Loewenstein, and O’Donoghue (2002) provide a review. 
Table A1

Comparison of Sample to the National Adult Population ${ }^{\mathrm{a}}$

Demographic Variable

Survey Participants US Adult Population $(\mathrm{n}=2,914)$

Percent

Percent

Employment Status (16 years or older)

Employed

60.4

62.3

Age

18 - 24 years old

13.6

13.3

25 - 34 years old

20.5

18.3

35 - 44 years old

19.2

20.4

45 - 54 years old

18.4

18.7

55 - 64 years old

11.9

12.2

64 - 74 years old

11.8

8.4

75 years old or older

4.6

8.1

\section{Educational Attainment}

Less than HS $\quad 18.8$

15.4

HS Diploma or higher

59.3

57.4

Bachelor or higher

21.8

27.2

Race / Ethnicity

White

80.0

81.9

Black/African-American

13.3

11.8

American Indian or Alaska Native

1.8

0.9

Asian/Pacific Islander/Other

4.8

5.5

Race / Ethnicity of Household

Hispanic

10.2

12.1

\section{Gender}

Male

50.7

48.5

Female

49.3

51.5

\section{Marital Status}

Married

56.5

58.8

Single (never married)

26.5

24.4

Divorced

11.7

10.2

Widowed

5.3

6.6

Household Income (2002)

Less than $\$ 15,000$

15.6

16.1

$\$ 15,000$ to $\$ 24,999$

11.7

13.2 
$\$ 25,000$ to $\$ 34,999$

12.1

18.8

12.3

$\$ 35,000$ to $\$ 49,999$

17.3

15.1

$\$ 50,000$ to $\$ 74,999$

24.5

18.3

$\$ 75,000$ or more

25.1

a Statistical Abstract of the United States, 2004-5. 2003 adult population (18 years+), unless otherwise noted. 
Table A2

Conditional Logit Estimates of Policy Choice, Scope Test

Coefficient (Std. Error)

\begin{tabular}{|c|c|c|c|c|}
\hline Variable & \multicolumn{2}{|c|}{ Question 1} & \multicolumn{2}{|c|}{ Full Sample } \\
\hline Water Quality Improvement 10 & -- & $\begin{array}{l}0.8859 * * * \\
(0.0890)\end{array}$ & -- & $\begin{array}{l}0.8545 * * * \\
(0.0352)\end{array}$ \\
\hline Water Quality Improvement 15 & -- & $\begin{array}{l}1.2765^{* * * *} \\
(0.1282)\end{array}$ & -- & $\begin{array}{l}1.1397 * * * \\
(0.0503)\end{array}$ \\
\hline Water Quality Improvement 20 & -- & $\begin{array}{l}1.9108 * * * \\
(0.1168)\end{array}$ & -- & $\begin{array}{l}1.8535 * * * \\
(0.0428)\end{array}$ \\
\hline Water Quality Improvement & $\begin{array}{l}0.1348 * * * \\
(0.0055)\end{array}$ & -- & $\begin{array}{l}0.1205 * * * \\
(0.0022)\end{array}$ & -- \\
\hline Delay 2 Years & -- & $\begin{array}{l}-1.0424 * * * \\
(0.0876)\end{array}$ & -- & $\begin{array}{l}-0.7511 \text { *** } \\
(0.0293)\end{array}$ \\
\hline Delay 4 Years & -- & $\begin{array}{l}-1.0745^{* * *} \\
(0.0981)\end{array}$ & -- & $\begin{array}{l}-1.0112 * * * \\
(0.0280)\end{array}$ \\
\hline Delay 6 Years & -- & $\begin{array}{l}-1.6196 * * * \\
(0.1485)\end{array}$ & -- & $\begin{array}{l}-1.5486 * * * \\
(0.0403)\end{array}$ \\
\hline Delay & $\begin{array}{l}-0.3013 * * * \\
(0.0135)\end{array}$ & -- & $\begin{array}{l}-0.2634 * * * \\
(0.0052)\end{array}$ & -- \\
\hline Cost 200 & -- & $\begin{array}{l}-0.5374 * * * \\
(0.0996)\end{array}$ & -- & $\begin{array}{l}-0.5322 * * * \\
(0.0280)\end{array}$ \\
\hline Cost 300 & -- & $\begin{array}{l}-1.0231 * * * \\
(0.0769)\end{array}$ & -- & $\begin{array}{l}-1.0814 * * * \\
(0.0285)\end{array}$ \\
\hline Cost 400 & -- & $\begin{array}{l}-1.4639 * * * \\
(0.1144)\end{array}$ & -- & $\begin{array}{l}-1.4381 * * * \\
(0.0399)\end{array}$ \\
\hline Cost & $\begin{array}{l}-0.0054 * * * \\
(0.0003)\end{array}$ & -- & $\begin{array}{l}-0.0052 * * * \\
(0.0001)\end{array}$ & -- \\
\hline
\end{tabular}

$* * *$ Coefficient is statistically significant at the 99 percent level, two-tailed test. 
Table A3

Conditional Logit and Mixed Logit Sensitivity Tests

\begin{tabular}{|c|c|c|c|c|}
\hline \multirow{2}{*}{$\begin{array}{l}\text { Variable } \\
\text { Water Quality Improvement }\end{array}$} & \multicolumn{2}{|c|}{$\begin{array}{l}\text { Conditional Logit Coefficient } \\
\text { (Std. Error) }\end{array}$} & \multicolumn{2}{|c|}{$\begin{array}{l}\text { Mixed Logit Coefficient } \\
\text { (Std. Deviation) }\end{array}$} \\
\hline & $0.1438 * * *$ & $0.1472 * * *$ & $\begin{array}{c}0.2236 \\
(01385)\end{array}$ & $\begin{array}{c}0.2169 \\
(01496)\end{array}$ \\
\hline Delay & $\begin{array}{l}-0.1497 * * * \\
(0.0141)\end{array}$ & $\begin{array}{l}-0.1339 * * * * \\
(0.0143)\end{array}$ & $\begin{array}{l}-0.5015 \\
(0.3781)\end{array}$ & $\begin{array}{l}-0.5944 \\
(0.5623)\end{array}$ \\
\hline Cost & $\begin{array}{l}-0.0054 * * * \\
(0.0001)\end{array}$ & $\begin{array}{l}-0.0053^{* * * *} \\
(0.0001)\end{array}$ & $\begin{array}{l}-0.0098 \\
(0.0067)\end{array}$ & $\begin{array}{l}-0.0103 \\
(0.0072)\end{array}$ \\
\hline Delay x Improvement & $\begin{array}{l}-0.0086^{* * * *} \\
(0.0010)\end{array}$ & $\begin{array}{l}-0.0147 * * * * \\
(0.0016)\end{array}$ & $\begin{array}{l}-0.0133 \\
(0.0210)\end{array}$ & $\begin{array}{l}-0.0235 \\
(0.0253)\end{array}$ \\
\hline$(\text { Delay })^{2} \mathrm{x}$ Improvement & -- & $\begin{array}{l}0.0009^{* * * *} \\
(0.0002)\end{array}$ & -- & $\begin{array}{c}0.0021 \\
(0.0065)\end{array}$ \\
\hline
\end{tabular}

***Coefficient is statistically significant at the 99 percent level, two-tailed test. 
Figure 1

Water Quality Survey Policy Choice ${ }^{\mathrm{a}}$

\begin{tabular}{|c|c|c|c|}
\hline \multicolumn{4}{|c|}{$\begin{array}{l}\text { Imagine again that you have recently moved to another region of the country, where } \\
\text { water quality is } \mathbf{5 0 \%} \text { Good. }\end{array}$} \\
\hline \multicolumn{4}{|c|}{$\begin{array}{l}\text { Imagine that the government is considering several policies that would temporarily } \\
\text { increase water quality in your region. Once the policy is in effect, the improvement lasts } \\
\text { for five years, then water quality returns to its previous level. Regardless of when the } \\
\text { improvement begins, the cost of each begins immediately and continues for five years. }\end{array}$} \\
\hline \multicolumn{4}{|c|}{ Which of the three policies below would you most prefer? } \\
\hline & Policy 1 & Policy 2 & Policy 3 \\
\hline $\begin{array}{l}\text { Year When Improvement } \\
\text { Begins }\end{array}$ & Now & $\begin{array}{l}2 \text { Years From } \\
\text { Now }\end{array}$ & $\begin{array}{l}4 \text { Years From } \\
\text { Now }\end{array}$ \\
\hline $\begin{array}{l}\text { Amount of Water } \\
\text { Improvement }\end{array}$ & $5 \%$ & $10 \%$ & $15 \%$ \\
\hline Cost of Policy Per Year & $\$ 100$ & $\$ 200$ & $\$ 300$ \\
\hline $\begin{array}{l}\text { Which Policy Would You } \\
\text { Prefer }\end{array}$ & $\begin{array}{c}\text { Policy } 1 \\
*\end{array}$ & $\begin{array}{c}\text { Policy } 2 \\
*\end{array}$ & $\underset{*}{\text { Policy } 3}$ \\
\hline
\end{tabular}

a The survey included the following policy variations-Amount of Water Quality Improvement: $5 \%, 10 \%, 15 \%$, or 20\%; Cost of Policy: $\$ 100, \$ 200, \$ 300$, or $\$ 400$; Timing of Improvement: Now, 2 Years From Now, 4 Years From Now, and 6 Years From Now. 
Figure 2

Discount Factors Predicted by Quadratic Delay Specification

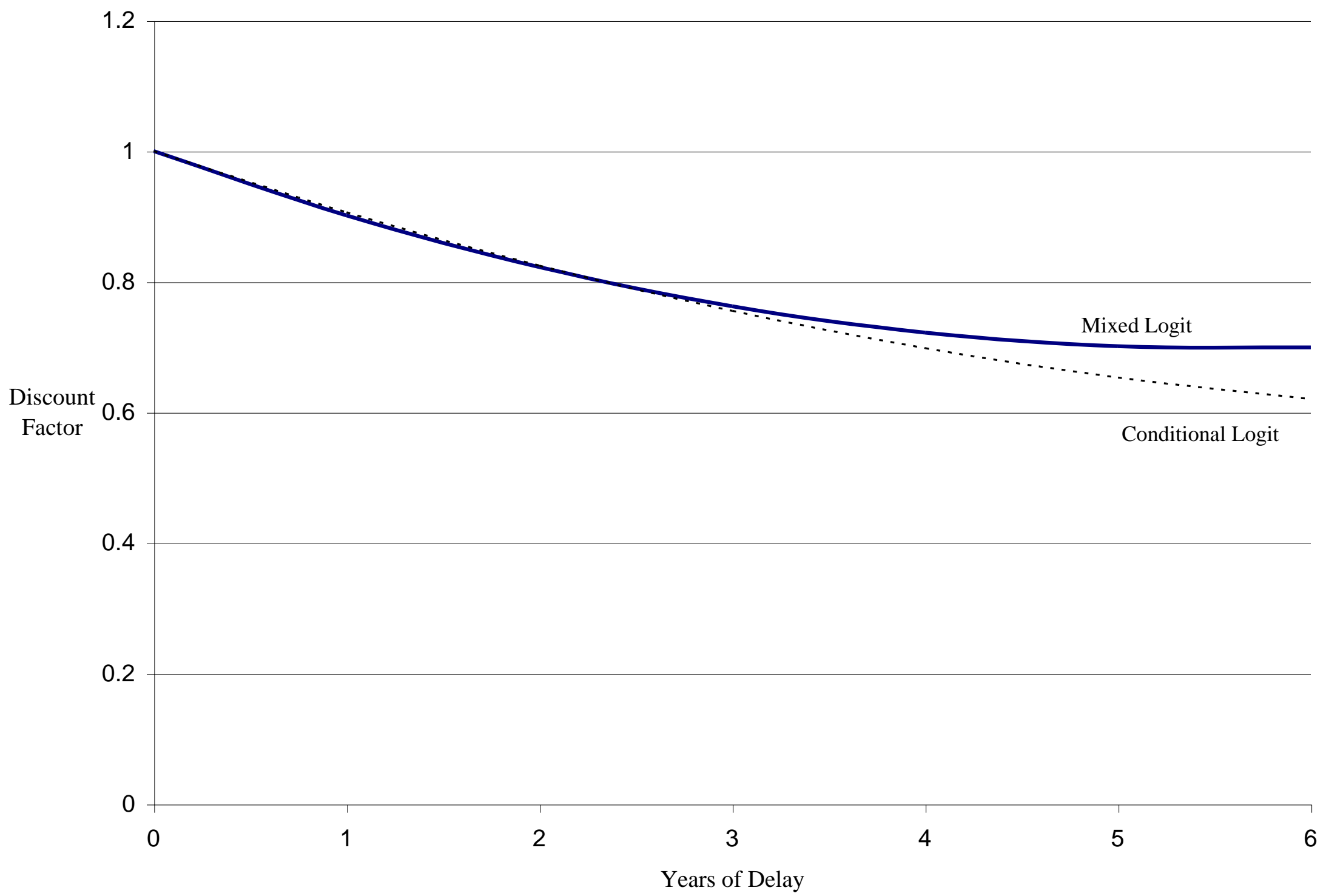


Table 1

Conditional Logit and Mixed Logit Estimates of Policy Choice

\begin{tabular}{lll} 
Variable & $\begin{array}{c}\text { Conditional Logit } \\
\text { Coefficient (Std. Error) }\end{array}$ & $\begin{array}{c}\text { Mixed Logit Coefficient } \\
\text { (Std. Deviation) }\end{array}$ \\
\hline Water Quality Improvement & $\begin{array}{l}0.1483 * * * \\
\text { Delay }\end{array}$ & 0.3098 \\
& $-0.1337 * * *$ & $(0.1605)$ \\
Cost & $(0.0144)$ & -0.3387 \\
& $-0.0053 * * *$ & $(0.3336)$ \\
Delay 2 Years x Improvement & $(0.0001)$ & -0.0111 \\
& $-0.0348^{* * *}$ & $(0.0086)$ \\
Delay 4 Years x Improvement & $(0.0031)$ & -0.0657 \\
& $-0.0410^{* * *}$ & $(0.0603)$ \\
Delay 6 Years x Improvement & $(0.0045)$ & -0.0818 \\
& $-0.0583 * * *$ & $(0.0658)$ \\
\hline
\end{tabular}

***Coefficient is statistically significant at the 99 percent level, two-tailed test. 
Table 2

95\% Confidence Intervals for Discount Factors and Rates of Time Preference

\begin{tabular}{|c|c|c|c|c|}
\hline \multirow[b]{2}{*}{ Period of Delay } & \multicolumn{2}{|c|}{ Discount Factor } & \multicolumn{2}{|c|}{ Rate of Time Preference } \\
\hline & $\delta$ & $\begin{array}{l}\text { 95\% Confidence } \\
\text { Interval }\end{array}$ & $\mathrm{r}(\%)$ & $\begin{array}{c}\text { 95\% Confidence } \\
\text { Interval }\end{array}$ \\
\hline $\begin{array}{r}\text { Full Sample: } \\
\text { 0-2 Years } \\
\text { 2-4 Years } \\
\text { 4-6 Years }\end{array}$ & $\begin{array}{l}0.875 \\
0.922 \\
0.920\end{array}$ & $\begin{array}{l}(0.855,0.895) \\
(0.906,0.938) \\
(0.903,0.937)\end{array}$ & $\begin{array}{r}14.32 \\
8.42 \\
8.70\end{array}$ & $\begin{array}{r}(11.79,16.97) \\
(6.56,10.35) \\
(6.75,10.71)\end{array}$ \\
\hline $\begin{array}{l}\text { Visits to Lakes and } \\
\text { Rivers: } \\
\text { 0-2 Years } \\
\text { 2-4 Years } \\
\text { 4-6 Years }\end{array}$ & $\begin{array}{l}0.902 \\
0.952 \\
0.945\end{array}$ & $\begin{array}{l}(0.878,0.926) \\
(0.933,0.970) \\
(0.926,0.963)\end{array}$ & $\begin{array}{r}10.84 \\
5.10 \\
5.83\end{array}$ & $\begin{array}{l}(7.99,13.84) \\
(3.05,7.22) \\
(3.79,7.97)\end{array}$ \\
\hline $\begin{array}{l}\text { No Visits to Lakes or } \\
\text { Rivers: } \\
\text { 0-2 Years } \\
\text { 2-4 Years } \\
\text { 4-6 Years }\end{array}$ & $\begin{array}{l}0.814 \\
0.848 \\
0.854\end{array}$ & $\begin{array}{l}(0.777,0.850) \\
(0.815,0.881) \\
(0.815,0.894)\end{array}$ & $\begin{array}{l}22.91 \\
17.94 \\
17.05\end{array}$ & $\begin{array}{l}(17.61,28.70) \\
(13.51,22.71) \\
(11.92,22.68)\end{array}$ \\
\hline
\end{tabular}


Table 3

Average and Marginal Rates of Time Preference

Average Total Average Rates of Marginal Rates of Hyperbolic Discount Factor Time Preference (\%) Time Preference (\%) Parameter $\beta^{*}$

Time Period $\delta_{0 \mathrm{~g}}=\delta^{\mathrm{g}}$

$r_{\mathrm{og}}$ $r_{g-2, g}$

Conditional Fixed Effect Logit Estimates:

2 years

0.77

14.3

14.3

$--$

4 years

0.72

8.4

2.8

0.48

6 years

0.61

8.7

9.3

0.58

$\underline{\text { Mixed Logit Estimates: }}$

2 years

0.79

12.7

12.7

4 years

0.74

8.0

3.5

0.53

6 years

0.63

7.9

7.7

0.61

* These $\beta$ values are calculated using the comparison of the estimates for the years indicated to the estimates for a delay of two years. 
Table 4

Conditional Logit Estimates with Delay-Improvement Interactions ${ }^{\mathrm{a}}$

\begin{tabular}{|c|c|c|c|}
\hline & Full Sample & $\begin{array}{c}\text { Visits to Lakes or } \\
\text { Rivers }\end{array}$ & $\begin{array}{c}\text { No Visits to } \\
\text { Lakes or Rivers }\end{array}$ \\
\hline Cost & $\begin{array}{l}-0.0053 * * * \\
(0.0001)\end{array}$ & $\begin{array}{l}-0.0053 * * * \\
(0.0001)\end{array}$ & $\begin{array}{l}-0.0052 * * * \\
(0.0002)\end{array}$ \\
\hline $\begin{array}{l}\text { Water Quality } \\
\text { Improvement }\end{array}$ & $\begin{array}{l}0.1483 * * * \\
(0.0036)\end{array}$ & $\begin{array}{l}0.1513 * * * \\
(0.0045)\end{array}$ & $\begin{array}{l}0.1417 * * * \\
(0.0063)\end{array}$ \\
\hline Delay & $\begin{array}{l}-0.1337 * * * \\
(0.0144)\end{array}$ & $\begin{array}{l}-0.1780 * * * \\
(0.0178)\end{array}$ & $\begin{array}{l}-0.0498 * * \\
(0.0245) \\
\end{array}$ \\
\hline $\begin{array}{l}\text { Delay } 2 \text { years x } \\
\text { Water Quality } \\
\text { Improvement }\end{array}$ & $\begin{array}{l}-0.0348 * * * \\
(0.0031)\end{array}$ & $\begin{array}{l}-0.0281 * * * \\
(0.0038)\end{array}$ & $\begin{array}{l}-0.0479 * * * \\
(0.0053)\end{array}$ \\
\hline $\begin{array}{l}\text { Delay } 4 \text { years x } \\
\text { Water Quality } \\
\text { Improvement }\end{array}$ & $\begin{array}{l}-0.0410 * * * \\
(0.0045)\end{array}$ & $\begin{array}{l}-0.0273 * * * \\
(0.0056)\end{array}$ & $\begin{array}{l}-0.0684 * * * \\
(0.0078)\end{array}$ \\
\hline $\begin{array}{l}\text { Delay } 6 \text { years x } \\
\text { Water Quality } \\
\text { Improvement }\end{array}$ & $\begin{array}{l}-0.0583 * * * \\
(0.0061)\end{array}$ & $\begin{array}{l}-0.0436 * * * \\
(0.0075)\end{array}$ & $\begin{array}{l}-0.0866 * * * \\
(0.0105)\end{array}$ \\
\hline
\end{tabular}

a Notes: ** Significant at the 0.05 level; *** significant at the 0.01 level; standard errors are in parentheses. 
Table 5

Conditional Logit Estimates with Personal Characteristic Interactions ${ }^{\mathrm{a}}$

\begin{tabular}{|l|l|l|c|c|}
\hline Variable Set & Full Sample & $\begin{array}{c}\text { Visits to Lakes } \\
\text { or Rivers }\end{array}$ & $\begin{array}{c}\text { No Visits to } \\
\text { Lakes or Rivers }\end{array}$ \\
\hline Main Effects & Cost & $\begin{array}{l}-0.0053 * * * \\
(0.0001)\end{array}$ & $\begin{array}{l}-0.0053 * * * \\
(0.0001)\end{array}$ & $-0.0052 * * *$ \\
& Water Quality & $0.1214 * * *$ & $0.1291 * * *$ & $(0.0002)$ \\
\cline { 2 - 5 } & Improvements & $(0.0022)$ & $(0.0028)$ & $0.1020 * * *$ \\
\cline { 2 - 5 } & Delay & $-0.2670 * * *$ & $-0.2795 * * *$ & $-0.2448 * * *$ \\
& $(0.0053)$ & $(0.0065)$ & $(0.0096)$ \\
\hline
\end{tabular}

\begin{tabular}{|c|c|c|c|c|}
\hline \multirow[t]{8}{*}{$\begin{array}{l}\text { Cost } \\
\text { Interactions }\end{array}$} & Age & $\begin{array}{c}6.88 \mathrm{e}-6 \\
(6.29 \mathrm{e}-6)\end{array}$ & $\begin{array}{l}1.39 \mathrm{e}-5 * \\
(7.87 \mathrm{e}-6)\end{array}$ & $\begin{array}{l}-4.58 e-6 \\
(1.07 e-5)\end{array}$ \\
\hline & Black & $\begin{array}{l}0.0006 * \\
(0.0003)\end{array}$ & $\begin{array}{c}0.0006 \\
(0.0004)\end{array}$ & $\begin{array}{c}0.0005 \\
(0.0004)\end{array}$ \\
\hline & Female & $\begin{array}{l}0.0004 * * \\
(0.0002)\end{array}$ & $\begin{array}{c}0.0004 \\
(0.0003)\end{array}$ & $\begin{array}{c}0.0005 \\
(0.0004)\end{array}$ \\
\hline & Education & $\begin{array}{l}-5.14 e-5 \\
(4.23 e-5)\end{array}$ & $\begin{array}{l}-5.57 e-5 \\
(5.17 e-5)\end{array}$ & $\begin{array}{l}-4.67 e-5 \\
(7.43 e-5)\end{array}$ \\
\hline & Income & $\begin{array}{l}9.75 \mathrm{e}-6 * * * \\
(2.85 \mathrm{e}-6)\end{array}$ & $\begin{array}{l}1.29 \mathrm{e}-5 * * * \\
(3.55 \mathrm{e}-6)\end{array}$ & $\begin{array}{c}3.78 \mathrm{e}-6 \\
(4.87 \mathrm{e}-6)\end{array}$ \\
\hline & $\begin{array}{l}\text { Environmental } \\
\text { group member }\end{array}$ & $\begin{array}{l}0.0014 * * * \\
(0.0005)\end{array}$ & $\begin{array}{l}0.0012 * * \\
(0.0005)\end{array}$ & $\begin{array}{l}0.0019 * \\
(0.0010)\end{array}$ \\
\hline & $\begin{array}{l}\text { Lake acres per } \\
\text { state square mile }\end{array}$ & $\begin{array}{c}1.51 \mathrm{e}-5 \\
(1.16 \mathrm{e}-5)\end{array}$ & $\begin{array}{l}1.74 \mathrm{e}-5 \\
(1.43 \mathrm{e}-5)\end{array}$ & $\begin{array}{l}1.15 e-5 \\
(1.98 \mathrm{e}-5)\end{array}$ \\
\hline & $\begin{array}{l}\text { Visited a lake or } \\
\text { river, last } 12 \\
\text { months }\end{array}$ & $\begin{array}{l}-3.23 e-5 \\
(0.0002)\end{array}$ & $\begin{array}{l}-- \\
--\end{array}$ & $\begin{array}{l}- \\
--\end{array}$ \\
\hline
\end{tabular}


Table 5 Continued

\begin{tabular}{|c|c|c|c|c|}
\hline \multirow{9}{*}{$\begin{array}{l}\text { Water } \\
\text { Quality } \\
\text { Improvement } \\
\text { Interactions }\end{array}$} & & Full Sample & $\begin{array}{c}\text { Visits to Lakes or } \\
\text { Rivers }\end{array}$ & $\begin{array}{c}\text { No Visits to } \\
\text { Lakes or Rivers }\end{array}$ \\
\hline & Age & $\begin{array}{l}-0.0003 * * \\
(0.0001)\end{array}$ & $\begin{array}{l}-0.0005 * * * \\
(0.0002)\end{array}$ & $\begin{array}{c}0.0003 \\
(0.0002) \\
\end{array}$ \\
\hline & Black & $\begin{array}{l}-0.0224 * * * \\
(0.0063)\end{array}$ & $\begin{array}{l}-0.0321 * * * \\
(0.0092)\end{array}$ & $\begin{array}{l}-0.0091 \\
(0.0088)\end{array}$ \\
\hline & Female & $\begin{array}{l}-0.0039 \\
(0.0044) \\
\end{array}$ & $\begin{array}{l}-0.0006 \\
(0.0055)\end{array}$ & $\begin{array}{l}-0.0109 \\
(0.0075)\end{array}$ \\
\hline & Education & $\begin{array}{l}0.0030 * * * \\
(0.0009)\end{array}$ & $\begin{array}{l}0.0037 * * * \\
(0.0011)\end{array}$ & $\begin{array}{c}0.0015 \\
(0.0015)\end{array}$ \\
\hline & Income & $\begin{array}{c}7.54 \mathrm{e}-5 \\
(6.03 \mathrm{e}-5) \\
\end{array}$ & $\begin{array}{c}4.70 e-5 \\
(7.53 e-5) \\
\end{array}$ & $\begin{array}{c}0.0001 \\
(0.0001) \\
\end{array}$ \\
\hline & $\begin{array}{l}\text { Environmental } \\
\text { group member }\end{array}$ & $\begin{array}{c}0.0084 \\
(0.0100)\end{array}$ & $\begin{array}{c}0.0032 \\
(0.0113)\end{array}$ & $\begin{array}{c}0.0275 \\
(0.0218)\end{array}$ \\
\hline & $\begin{array}{l}\text { Lake acres per } \\
\text { state square mile }\end{array}$ & $\begin{array}{c}0.0002 \\
(0.0002)\end{array}$ & $\begin{array}{c}0.0003 \\
(0.0003)\end{array}$ & $\begin{array}{r}1.61 \mathrm{e}-5 \\
(0.0004)\end{array}$ \\
\hline & $\begin{array}{l}\text { Visited a lake or } \\
\text { river, last } 12 \\
\text { months }\end{array}$ & $\begin{array}{l}0.0260 * * * \\
(0.0047)\end{array}$ & $\begin{array}{l}-- \\
--\end{array}$ & $\begin{array}{l}-- \\
--\end{array}$ \\
\hline
\end{tabular}

\begin{tabular}{|c|c|c|c|c|}
\hline \multirow[t]{8}{*}{$\begin{array}{l}\text { Delay } \\
\text { Interactions }\end{array}$} & Age & $\begin{array}{l}-0.0022 * * * \\
(0.0003)\end{array}$ & $\begin{array}{l}-0.0018 * * * \\
(0.0004)\end{array}$ & $\begin{array}{l}-0.0028 * * * \\
(0.0005)\end{array}$ \\
\hline & Black & $\begin{array}{l}-0.0728 * * * \\
(0.0159)\end{array}$ & $\begin{array}{l}-0.1032 * * * \\
(0.0233)\end{array}$ & $\begin{array}{l}-0.0476 * * \\
(0.0222)\end{array}$ \\
\hline & Female & $\begin{array}{l}-0.0150 \\
(0.0105)\end{array}$ & $\begin{array}{l}-0.0263 * * \\
(0.0128)\end{array}$ & $\begin{array}{c}0.0075 \\
(0.0184)\end{array}$ \\
\hline & Education & $\begin{array}{l}-0.0016 \\
(0.0021)\end{array}$ & $\begin{array}{l}-0.0035 \\
(0.0026)\end{array}$ & $\begin{array}{c}0.0025 \\
(0.0037)\end{array}$ \\
\hline & Income & $\begin{array}{c}1.57 \mathrm{e}-5 \\
(1.45 \mathrm{e}-5)\end{array}$ & $\begin{array}{l}0.0005 * * * \\
(0.0002)\end{array}$ & $\begin{array}{l}-4.51 \mathrm{e}-4 * \\
(2.57 \mathrm{e}-4)\end{array}$ \\
\hline & $\begin{array}{l}\text { Environmental } \\
\text { group member }\end{array}$ & $\begin{array}{l}-0.0339 \\
(0.0239)\end{array}$ & $\begin{array}{l}-0.0451 * \\
(0.0271)\end{array}$ & $\begin{array}{l}-0.0043 \\
(0.0517)\end{array}$ \\
\hline & $\begin{array}{l}\text { Lake acres per } \\
\text { state square mile }\end{array}$ & $\begin{array}{l}-0.0010 * \\
(0.0006)\end{array}$ & $\begin{array}{l}-0.0010 \\
(0.0007)\end{array}$ & $\begin{array}{l}-0.0010 \\
(0.0010)\end{array}$ \\
\hline & $\begin{array}{l}\text { Visited a lake or } \\
\text { river, last } 12 \\
\text { months }\end{array}$ & $\begin{array}{l}-0.0358 * * * \\
(0.0115)\end{array}$ & -- & -- \\
\hline
\end{tabular}

${ }^{\text {a }}$ Notes: * significant at the 0.10 level; $* *$ significant at the 0.05 level; and $* * *$ significant at the 0.01 level, two-tailed test. All variables are zero centered. 